\title{
ESCOLA DE TEMPO INTEGRAL VERSUS FORMAÇÃO HUMANA INTEGRAL: EXPERIÊNCIAS DE UMA ESCOLA DO MUNICÍPIO DE CAMPINAS, SÃO PAULO
}

\author{
Elaine Cristina Panini Messa ${ }^{l}$ (D) \\ Juliana Cristina Chaves Buldrin Baiocchi ${ }^{1}$ (D) \\ Renato Horta Nunes ${ }^{I}$ (D) \\ Simone Cecilia Fernandes ${ }^{l}$ (D)
}

RESUMO: Este artigo pretende socializar algumas práticas educativas desenvolvidas na Escola Municipal de Educação Integral (EEI) Dr. João Alves dos Santos, localizada na região norte da cidade de Campinas, São Paulo. Pretende também apresentar consideraçóes a respeito do conceito de Educaçáo Integral na perspectiva da formação humana, buscando refletir sobre suas políticas de implementação. Interessa-nos olhar para as necessidades dos estudantes e dos educadores, provocando reflexôes e narrativas que mobilizam o jeito de ver/fazer o trabalho educativo.

Palavras-chave: Escola integral. Formação humana integral. Cotidiano escolar.

\section{Full-time school versus full-time human training: experiences of a school of the city of Campinas, Sáo Paulo, Brazil}

ABSTRACT: This article intends to socialize some educational practices developed in the Municipal School of Full-time

${ }^{1}$ Rede Municipal de Educação - Campinas (SP), Brasil. E-mails: elainecrismessa@bol.com.br, jbuldrin@gmail.com, rhortanunes@gmail.com, si.cecifernandes@gmail.com

DOI: $10.1590 / C C 0101-32622019219113$ 
Education (Escola Municipal de Educaçâo Integral - EEI Dr. João Alves dos Santos), located in the northern region of the city of Campinas, São Paulo, Brazil. It also intends to raise discussions about the concept of full-time education in the perspective of human formation, seeking to reflect on its implementation. We are interested in looking at the needs of students and educators, provoking reflections and narratives that mobilize the way to see/do the educational work.

Keywords: Integral school. Full-time human education. Everyday school.

Se as coisas são inatingiveis...ora! Não é motivo para não querê-las... Que tristes os caminhos, se não fora A presença distante das estrelas.

(Mario Quintana)

\section{INTRODUÇÃO}

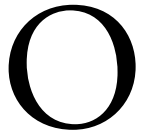

artigo a seguir apresenta, inicialmente, breves considerações a respeito do conceito de Educação Integral e de formação humana, a fim de buscar reflexôes em torno das políticas públicas educacionais e o currículo escolar. Em seguida, explicita sobre o processo de implementaçáo da escola de tempo integral no município de Campinas, São Paulo, apresentando um pouco de sua estrutura. Por fim, socializa algumas experiências desenvolvidas na escola, que envolvem a busca da autonomia nos processos criativos dos estudantes, bem como o desenvolvimento de projetos que buscam potencializar o trabalho coletivo entre educadores e alunos. Para tanto, buscamos o diálogo e a interlocuçáo com autores que nos ajudam a refletir sobre a temática, tais como Arroyo (2013), Cavaliere (2002), entre outros. 


\section{EDUCAÇÃO E FORMAÇÃO HUMANA INTEGRAL}

Brincar com crianças não é perder tempo, é ganha-lo; se é triste ver meninos sem escola, mais triste ainda é vê-los sentados enfileirados em salas, sem ar, com exercícios estéreis, sem valor para a formação do homem.

(Carlos Drummond de Andrade)

Tratar da temática da educação que considere a formação humana em sua integralidade nos remete pensar sobre os sentidos dados às dimensóes da condição humana dentro e fora da instituição escolar. O dicionário Aurélio (2010, p. 432) define o termo "integral" como "total, inteiro, global, sem diminuiçóes nem restriçóes". Embora possa parecer um pleonasmo associar o termo humano ao integral, nos parece necessário ressaltar que a condição humana é constituída de múltiplas dimensões, mas a formação pode não atender às suas necessidades.

Quando o termo "Educação Integral” começou a circular como prioridade no conjunto das políticas públicas educacionais, rapidamente foi associado ao contexto da escola de tempo integral. Cavaliere (2002, p. 253) ajuda-nos entender que o termo "educação integral", na perspectiva do movimento renovador do início do século XX, "refletia a necessidade de reencontrar a vocaçáo da escola na sociedade urbana, de massas, industrializada e democrática”, e estava pautado na corrente pedagógica escolanovista ${ }^{1}$. Esse autor afirma ainda:

A reformulação da escola esteve associada à valorização da atividade ou experiência em sua prática cotidiana. $\mathrm{O}$ entendimento da educação como vida, e não como preparação para a vida, foi a base dos diversos movimentos que a formaram [...]. Toda a discussão em torno da questão do método, de uma nova visão de como se aprende, continha a ideia de um religamento entre os conhecimentos escolares e a vida em sua plenitude (CAVALIERE, 2002, p. 253). 
Compreendemos que, nos dias de hoje, ainda há a necessidade de reinvenção da escola em uma perspectiva de rompimento com as práticas de escolarização tradicional, que pressupóem uma homogeneidade cultural.

Independentemente do tempo, seja ele ampliado ou não, a formação dos estudantes deve ser voltada a considerar a multidimensionalidade humana, e é nesse sentido que nós, educadores, propomo-nos a pensar e a buscar caminhos que nos permitam reinventar um currículo, que contemple a heterogeneidade, a pluralidade cultural, o estímulo à capacidade criadora.

Pensar em uma formação que privilegie a formação humana nos aproxima ampliar a reflexão no campo do currículo, pois muito além do ensino dos conteúdos escolares, para a escola, o estudante traz sua vida e tudo o que o constitui. Nesse sentido, Arroyo (2013, p. 15) convida-nos a refletir sobre a identidade docente, no "redemoinho das tensóes" do cotidiano, e alerta-nos:

A formação pedagógica e docente gira toda para conformar o protótipo de profissional fiel ao currículo, tradutor e transmissor dedicado e competente de como ensinar-aprender os conteúdos definidos nas diretrizes do currículo e avaliados nas provas oficiais. Náo apenas o sistema escolar, mas a escola, a sala de aula, a organização do trabalho docente gira nesse território. Estão amarradas ao ordenamento curricular (ARROYO, 2013, p. 15).

Assim sendo, faz-se necessário um rompimento do trabalho docente que seja focado exclusivamente no ordenamento curricular, para que possamos nos aproximar de práticas emancipadoras, que explorem as diversas dimensóes das capacidades humanas.

Sabemos que, para fins do cumprimento da meta número 6 (seis) estabelecida no Plano Nacional da Educação (PNE) (2014-2024), a escola em tempo integral tem sido implementada como política de educação que pretende, sobretudo, garantir que os estudantes estejam mais tempo no espaço escolar: "Oferecer educação em tempo integral em, no mínimo, 50\% (cinquenta por cento) das escolas públicas, de forma a 
atender, pelo menos, $25 \%$ (vinte e cinco por cento) dos(as) alunos(as) da educação básica” (BRASIL, 2014)2.

Porém, as condiçóes dadas pelo poder público para que haja essa garantia tem sido pauta de grandes discussóes, pois há ainda um caminho longo a ser percorrido para que de fato a escola tenha condiçóes de atender aos estudantes em sua integralidade e em tempo integral.

Em contrapartida, o documento recentemente homologado pelo Ministério da Educação, que estabelece a Base Nacional Comum Curricular (BNCC), destaca o compromisso das políticas educacionais com a educação integral. Tal documento traz em seu bojo o compromisso com a Educação Integral reconhecendo a necessidade de a educação básica privilegiar a formaçáo e o desenvolvimento humano global:

O que implica compreender a complexidade e a não linearidade desse desenvolvimento, rompendo com visóes reducionistas que privilegiam ou a dimensão intelectual (cognitiva) ou a dimensão afetiva. Significa, ainda, assumir uma visão plural, singular e integral da criança, do adolescente, do jovem e do adulto - considerando-os como sujeitos de aprendizagem - e promover uma educação voltada ao seu acolhimento, reconhecimento e desenvolvimento pleno, nas suas singularidades e diversidades. Além disso, a escola, como espaço de aprendizagem e de democracia inclusiva, deve se fortalecer na prática coercitiva de náo discriminaçáo, náo preconceito e respeito às diferenças e diversidades. Independentemente da duração da jornada escolar, o conceito de educação integral com o qual a BNCC está comprometida se refere à construção intencional de processos educativos que promovam aprendizagens sintonizadas com as necessidades, as possibilidades e os interesses dos estudantes e, também, com os desafios da sociedade contemporânea. Isso supóe considerar as diferentes infâncias e juventudes, as diversas culturas juvenis e seu potencial de criar novas formas de existir (BRASIL, 2017, p. 14) ${ }^{3}$.

Portanto, no que diz respeito às intenções, percebemos que há, no documento oficial citado acima, o entendimento do termo "educação integral" que coaduna com princípios emancipadores, porém entendemos 
que a ampliação do número de escolas operando em tempo integral, mesmo que alcançando a meta estabelecida no PNE, não garante que a formação dos estudantes esteja de fato pautada em seu aspecto humano integral.

Entendemos que é urgente a ressignificação da escola como um espaço/tempo que referencie a educação como processo permanente de humanização e entendemos que os educadores, de forma coletiva, devem se mobilizar nessa busca. Uma educação que tenta romper com o modelo e a tradição escolar conteúdista/instrucionista, que carrega ainda um currículo estático e engessado, em um momento em que os efeitos das políticas educacionais, em geral, não colaboram para o alcance da educação que se pretende. E esse sistema, como aponta Arroyo (2013, p. 15), tende a deixar de fora a produção estética, ética, cultural na medida em que os conhecimentos validados esquecem a formação da plenitude de dimensóes que nos conformam como humanos desde a infância.

A seguir, importa apresentar de forma breve o movimento vivido pela escola no processo de implementação do tempo integral no município de Campinas.

\title{
IMPLEMENTAÇÃO DAS ESCOLAS DE TEMPO INTEGRAL NA REDE DE EDUCAÇÃO DE CAMPINAS, SÃO PAULO
}

\author{
Alongo-me \\ $o$ rio nasce \\ toda a vida. \\ Dá-se \\ ao mar a alma vivida. \\ A água amadurecida, \\ a face \\ ida. \\ $O$ rio sempre renasce \\ a morte é vida. \\ (João Guimarães Rosa)
}

No ano de 2014, em cumprimento às políticas nacionais de educação, a prefeitura municipal de Campinas iniciou o processo de 
implementação das escolas de tempo integral em duas unidades da rede de ensino. Em 2015, a EEI Dr. João Alves dos Santos também passou a atender os estudantes de ensino fundamental I e II em tempo integral. As primeiras escolas a estenderem o período de permanência dos estudantes foram regulamentadas por meio do "Projeto Piloto para a Escola de Educação Integral: uma proposta em construção no município de Campinas", apresentado em forma de decreto publicado no Diário Oficial do Município (DOM), de 10 de março de 2014, por meio da Resolução da Secretaria Municipal de Educação (SME) no 5/2014 (CAMPINAS, 2014), que estabelece diretrizes para o funcionamento administrativo e pedagógico dessas escolas, documento este que regulamentaria também, no ano seguinte, as atividades da escola em questáo e serviria como base para a reformulação dos projetos político-pedagógicos das escolas.

O documento apresenta os princípios da educação integral no município e ressalta que a ampliação da jornada, somente, não serve para elevar os índices de aprendizagem, mas que é preciso haver reflexão sobre as diferentes dimensões da educação integral, considerando o sujeito em sua dimensão cognitiva, corpórea e afetiva.

O documento também apresenta a busca por um trabalho que não seja fragmentado e atrela à matriz curricular a composição das 40 horas da jornada docente com horas/aulas semanais de 50 minutos, sendo 25 horas com os estudantes em atividade direta; 4 horas destinadas para a formação coletiva continuada; 2 horas para a formação coletiva docente; 3 horas para a reuniáo de planejamento entre pares; e 6 horas para o planejamento em local de livre escolha do professor. O projeto estabelece eixos de trabalho, tais como: trabalho e movimento estudantil, leitura, criação e expressão, cultura e ciência, direitos humanos, corpo e movimento, língua e cultura.

O processo de mudança de regime regular para integral dessas escolas provocou mobilização, debate e certa resistência por parte de alguns profissionais das unidades e da Secretaria de Educação, pois não houve amplo estudo prévio dos impactos para a necessária adequação estrutural e pedagógica demandadas pela nova proposta.

A então Escola Municipal de Ensino Fundamental (EMEF) Dr. João Alves dos Santos, que tinha períodos regulares nos turnos da 
manhã, da tarde e da noite (Educação de Jovens e Adultos - EJA), passou a funcionar das $7 \mathrm{~h} 50$ às $15 \mathrm{~h} 20$, atendendo aos estudantes do $1^{\circ}$ ao $9^{\circ}$ ano e mantendo a EJA no período noturno. Ao currículo foi incluído as disciplinas de Ética e Cidadania e Literatura, estendendo as aulas da grade curricular de seis para nove, formalizando, assim, o período integral, porém sem mudanças metodológicas significativas nas aulas dos estudantes.

O modo como se configura hoje a escola, as angústias e as pequenas conquistas vividas por essas experiências nos mobilizam a continuar percorrendo caminhos que nos levem à educaçáo que queremos. $\mathrm{Na}$ prática, ainda é preciso haver avanços na direção dos princípios elencados no documento, bem como a quebra de paradigmas em torno da forma de abordagem dos conteúdos por parte de alguns professores.

É preciso que superemos a ampliação da jornada traduzida na mera extensão do currículo. A luta por condiçóes de trabalho e valorização profissional deve ser constante, pois diante de um cenário de incertezas em um cotidiano que muitas vezes sugere estagnaçáo, tendência essa imposta por um sistema que prega a educação integral dos sujeitos em seu discurso, mas que restringe a atuaçáo dos educadores na busca por esse objetivo, que aligeira a formação dos professores e sua atuação nos espaços coletivos, que terceiriza e desmantela a educação pública, é imprescindível práticas de resistência que abram possibilidades para que o diálogo sobre as experiências emancipadoras se estenda.

Nesse sentido, essa narrativa e suas consideraçóes expressam o olhar de alguns profissionais que acompanharam esse processo ao longo desses anos, desde a indicação da escola pela SME até os dias de hoje, e que atuaram em alguns momentos em representaçóes do segmento dos professores e das professoras em reunióes destinadas à discussão de aspectos organizacionais ou mesmo legais para a gênese da escola que temos hoje.

Assim, na tentativa de experienciar os princípios da Educação Integral com vistas às diversas dimensóes da formação humana, apresentaremos a seguir algumas práticas que consideramos significativas desenvolvidas no chão da escola. 


\title{
PROJETOS E PROCESSOS CRIATIVOS NA EDUCAÇÃO INTEGRAL: EXPERIÊNCIAS NA ESCOLA
}

\author{
Acho que o quintal que a gente brincou é maior do \\ que a cidade. A gente só descobre isso depois de grande. \\ A gente descobre que o tamanho das coisas há que ser \\ medido pela intimidade que temos com as coisas.
}

(Manoel de Barros)

A escola de Educação Integral em tempo integral, mais que as demais escolas, tem grandes desafios quanto à relação entre convivência e ensino. Em nossa escola, essa relação é bastante discutida e algumas propostas têm sido implementadas, as quais apresentaremos neste tópico do artigo. As experiências aqui sistematizadas se inserem na dinâmica que envolve o cotidiano escolar, sendo que essas experiências compóem também saberes, no sentido apresentado por Larrosa (2002), como um processo de construçáo de sentidos à vida: "Este é o saber da experiência: o que se adquire no modo como alguém vai respondendo ao que vai lhe acontecendo ao longo da vida e no modo como vamos dando sentido ao acontecer do que nos acontece" (LARROSA, 2002, p. 27).

Os projetos e os processos descritos produzem essas experiências dotadas de sentidos, e que são atravessadas também por significativas relaçôes de poder. Sendo a experiência o lugar da formação dos sujeitos, esse lugar condensa lutas pelo sentido, como "um lugar de contestação: um espaço discursivo onde posiçóes de sujeitos e subjetividades diferentes e diferenciais são inscritas, reiteradas ou repudiadas" (BRAH, 2006, p. 361). Em nossa escola, os sentidos que alimentam as açóes buscam construir uma escola pública e democrática, laica e com qualidade social referenciada pelos sujeitos que vivem o seu cotidiano.

Para escrever sobre a convivência na unidade estamos considerando as relaçóes entre diferentes agentes: discentes, docentes, direção e funcionários. No que se refere aos discentes, em sua maioria, a convivência acontece permeada por relaçóes dialógicas. No entanto, diariamente, ocorrem situaçóes pontuais que se distanciam do diálogo e envolvem comunicação agressiva entre eles(as). Essa situação é corriqueira entre 
escolares (e não somente nas escolas com período integral) e demanda atenção para o fortalecimento de açóes que oportunizem outras maneiras de viver na escola, não demarcadas pela agressividade e sim por possibilidades dialógicas.

Nesse sentido, temos implementado algumas propostas, tais como a "equipe de ajuda" ${ }^{4}$ entre os(as) jovens do $6^{\circ}$ ao $9^{\circ}$ ano. Essa proposta funciona da seguinte maneira: as turmas escolhem, por meio de uma eleição em cada ano escolar, os(as) discentes que farão parte dessa equipe, tendo como critério a confiabilidade, a confiança que essa pessoa desperta entre as demais. O grupo de estudantes eleitos (estudantes escolhidos por cada turma por meio de voto) compóe a equipe de ajuda, e imersos nas relaçóes sociais e emocionais que envolvem ser estudante em nossa escola, agem auxiliando aqueles(as) estudantes que possuem dificuldades ou que estão enfrentando algum momento difícil no cotidiano escolar, com relação à convivência entre colegas no contexto. As equipes de ajuda se reúnem semanalmente e são acompanhadas por professores(as), que podem auxiliar em questóes mais complexas.

Essa é uma proposta que se encontra em processo de construção com discentes desde o ano de 2017, e busca agir no plano das relaçóes pessoais entre eles(as), visando ao bem-estar de todos(as) no contexto escolar. Há também propostas que buscam construir coletivamente a escola: a Comissão Própria de Avaliação (CPA), o Conselho de Escola, o Grêmio Estudantil e as Assembleias Gerais de Estudantes.

A CPA é uma comissão composta de todos os segmentos que se reúnem mensalmente com o objetivo de avaliá-la continuamente. A CPA conta com a participação dos alunos e das alunas representantes de salas (eleitos no início de cada ano letivo), representantes docentes, da direção e mãe de alunos(as). O segmento de funcionários não tem efetivamente participado das reunióes - fator que dificulta essa participação é a terceirização desses serviços. As discussóes que ocorrem na CPA têm como referência as demandas trazidas pelos representantes de salas, as quais são levantadas em assembleias de classe. Após a organização dessas reivindicaçóes na CPA, é realizada uma Assembleia Geral de Estudantes, tendo como pauta as demandas estudantis. Com relação ao segmento estudantil, a sequência dos acontecimentos fica assim organizada: Assembleias de Classes — reunião CPA — Assembleia Geral dos Estudantes. 
Dessa maneira, a participação estudantil no cotidiano da unidade, suas necessidades e vontades têm um canal de diálogo estabelecido, de escuta e possibilidade de construção coletiva do contexto escolar. No entanto, algumas propostas discentes esbarram na burocracia escolar ou envolvem mudanças estruturais, tais como a mudança do cardápio, a não exigência do uso de uniformes, mais estudos do meio fora do contexto escolar etc. Importante ressaltar que essa organização coletiva ainda não ocorre dessa maneira com os demais segmentos; embora seja uma reivindicação docente desde 2017, as assembleias docentes e de funcionários não estão pautadas no cotidiano escolar, o que torna o processo de construção coletiva da escola menos acessível e sem ampla participação de todos os segmentos de pessoas.

Outra possibilidade de construção coletiva do contexto escolar, considerando discentes, é o Grêmio Estudantil, que desde o ano de 2017, com a criação da Comissão Pró-Grêmio, esteve em processo de construção e que culminou com a sua eleição em maio de 2018. A comissão pró-grêmio elaborou o Estatuto Geral do Grêmio Estudantil e o apresentou em Assembleia Geral dos Estudantes, que o aprovaram e elegeram uma Comissão Eleitoral, composta de estudantes. A comissão organizou o processo eleitoral, tal como já estava descrito no estatuto, estabelecendo cronograma para a inscrição das chapas, período de divulgação das ideias e propostas, eleição, apuração dos votos e posse da chapa eleita. Todo o processo, desde a implementação da comissão pró-grêmio até a posse da chapa eleita, foi acompanhado por docentes que auxiliaram na compreensão dos processos democráticos e de organização postos em ação na eleição. O Grêmio Estudantil é algo novo na escola, e todos(as) estão construindo e aprendendo os significados de sua existência.

Outro projeto coletivo desenvolvido foi denominado, no cotidiano, como Monitoria, e tem sido implementado a partir da demanda estudantil por oficinas e brincadeiras diversificadas no período de tempo livre após o almoço. Os alunos e alunas interessados em desenvolver alguma oficina procuraram professores(as) para orientar e ajudar a organizá-la. Assim, algumas práticas se iniciaram nesses momentos, tais como as esportivas, e encontram-se sob a responsabilidade de discentes, com supervisão docente: basquetebol, vôlei três cortes, artilheirinho e futsal.

Por fim, dentro das práticas postas em ação junto aos jovens, destacamos algumas pesquisas realizadas pelos estudantes dentro do 
Programa PESCO 5 , as quais investigaram o contexto escolar considerando as relaçóes de gênero e o jogo de queimada, a autoimagem e a aceitação de si e o racismo velado e desvelado no cotidiano.

No ano de 2017 , a turma do $5^{\circ} \mathrm{B}$ investigou as oportunidades de aprender o gesto de "queimar" no jogo de queimada, observando diferentes turmas e quantidade de vezes que meninos e meninas executavam esse movimento, durante os dez primeiros minutos do jogo. Os dados revelaram que os meninos tiveram muito mais oportunidades de aprender os movimentos corporais requisitados para "queimar" durante um jogo de queimada, em uma relação percentual de $78 \%$ para eles e $22 \%$ para elas. Esses números desiguais foram semelhantes nas diferentes turmas observadas $\left(4^{\circ} \mathrm{A}, 4^{\circ} \mathrm{B}, 5^{\circ} \mathrm{A}, 5^{\circ} \mathrm{B}\right.$ e $\left.9^{\circ} \mathrm{B}\right)$.

Diante disso, observou-se que muitas práticas corporais e esportivas também se encontravam atravessadas por privilégios de gênero (os meninos com maiores oportunidades), o que demanda da escola a criação de oportunidades e iniciativas que tornem as práticas escolares com iguais oportunidades de aprender, com atenção especial aos seguintes momentos: horários do intervalo, aulas de educação física e projetos extraclasses. A turma do $5^{\circ} \mathrm{B}$, que pesquisou essa temática, sugeriu algumas medidas para a busca da equidade, tais como:

1) As meninas podem jogar mais, ter mais iniciativa para participar;

2) Parar de xingar o(a) outro(a);

3) As meninas precisam confiar mais nelas;

4) Os meninos têm que aprender que as meninas também sabem jogar;

5) As meninas passam a bola para eles porque os meninos pedem. Eles têm que aprender a não pedir a bola quando elas pegam;

6) Os meninos poderiam perceber que as meninas estão jogando.

A pesquisa e seus dados foram apresentados em uma assembleia geral e ainda estáo sendo trabalhados no cotidiano escolar.

Outro projeto de pesquisa desenvolvido esteve relacionado à identidade, e a turma que realizou a pesquisa foi o 90 A, em 2017. 
Eles(as) investigaram a rede de pertencimento social declarada pelas alunas e pelos alunos, inicialmente voltando para a autoimagem, observando se teria alguma parte do corpo que gostariam de mudar, utilizando um desenho com um boneco para se expressar sem necessidade de identificação. Os dados obtidos com os desenhos revelaram que os itens mais apontados foram o cabelo, o pé e o olho, nesta ordem. Alguns alunos e alunas pesquisadores(as) ficaram surpresos(as) com a reação de discentes que pintaram o boneco todo, revelando que estavam totalmente insatisfeitos com seus corpos.

Diante disso, alunos e alunas pesquisadores(as) apontaram a importância de trabalhar a autoestima e o apreço por si, seu corpo, por meio de palestras e outras açóes. Uma ação realizada foi uma "oficina de cabelos", na qual algumas alunas do $9^{\circ}$ ano fizeram penteados, vários tipos de trança, que foi um sucesso e contribuiu para o aumento da autoestima e do gostar de si.

Outro projeto desenvolvido no ano de 2017 foi sobre o "Racismo velado e desvelado" na escola, realizado pelo $9{ }^{\circ} \mathrm{B}$, o qual investigou a autodeclaração discente sobre a cor da pele. Essa pesquisa foi realizada no horário livre do almoço, somente com quem se dispôs a participar, na pracinha da escola.

Apenas $0,5 \%$ dos discentes se declararam negros, e foi observado um racismo desvelado, por meio de xingamentos, ofensas e brincadeiras preconceituosas que permearam o processo de autodeclaração na escola. Diante desses dados, apontou-se para a necessidade de ações afirmativas e formativas, integradas ao cotidiano de ensino, que visibilizem a história dos negros e das negras no Brasil e os aspectos da cultura afro-brasileira no currículo escolar.

Essas pesquisas foram realizadas por estudantes, sendo a temática de interesse discente escolhida por eles(as), sob supervisão e orientaçáo docente, e trouxeram aspectos da vida social na escola que, embora estejam presentes em outros espaços sociais, reproduzem-se no chão escolar e carecem de problematização a fim de construir um contexto escolar no qual preconceitos não se reproduzam, ousando construir maneiras de viver na escola que valorizem a diversidade nos modos de ser e de pensar o mundo. 
No início de 2018, deliberamos em assembleia que a formação continuada de professores seria escolhida pelo corpo docente e teria como principal objetivo tratar de algo que nos auxiliasse em nosso cotidiano escolar e por que não ser ministrada por um de nossos professores, tâo qualificados e cientes de nossas demandas. Por se tratar de uma escola de ensino fundamental I e II, temos necessidades diferentes; por esse motivo, nossa formação foi dividida em dois grupos. Nos ciclos I e II ( $1^{\circ}$ ao $5^{\circ}$ ano), a formaçáo está voltada para o estudo do movimento e da arte-terapia, que nos leva a refletir sobre a importância do movimento e da cultura para o crescimento e o desenvolvimento humano dos alunos. $\mathrm{O}$ curso tem nos proporcionado um autoconhecimento e um entrosamento maior, pois por meio de danças de roda, estudo da cultura popular brasileira, dinâmicas e expressóes artísticas estamos tendo oportunidade de conhecer um pouco melhor cada participante, suas dificuldades, suas fragilidades. O curso também nos possibilita refletir sobre nossos alunos e alunas de uma maneira diferente, afinal, eles(as) também estão nesse processo de aprendizagem, que gera vários sentimentos diferentes, e que precisam ser respeitados em sua integralidade.

Pensar no desenvolvimento integral do estudante tornou-se parte de nossa rotina, pois ele passa grande parte de seu tempo na escola, período que tem que ser aproveitado de maneiras diferenciadas. Por esse motivo, procuramos desenvolver trabalhos e projetos que tornem essa estadia na escola algo prazeroso e que gerem conhecimento que possa ser utilizado na vida dos estudantes, como o projeto de sustentabilidade que estamos desenvolvendo, no qual, por meio da recuperação dos canteiros e dos jardins da escola, eles têm a oportunidade de sair da sala de aula e aplicar na prática as próprias pesquisas e descobertas.

Procuramos construir uma escola em que o movimento faça parte da nossa rotina, porque acreditamos que isso é uma maneira de manifestar a inteligência, criar com a terra, com o corpo, explorar os espaços internos e os arredores, entender como as coisas acontecem e como devemos agir para que possamos aprender com isso, pois o fundamental da escola não são os conteúdos, mas o que faremos com eles. A integração entre os ciclos é outro ponto que vale destaque, pois são desenvolvidos projetos de monitoria, já mencionados anteriormente, nos quais os estudantes mais velhos auxiliam e ensinam os mais novos, como no caso do projeto de mobilidade que estamos desenvolvendo entre os $9^{\text {os }}$ anos 
e os alunos dos $3^{\text {os }}$ e $4^{\text {os }}$ anos. Nesse projeto, os estudantes mais velhos sinalizaram a escola e depois realizaram um tour com os mais novos, para explicar o motivo da sinalização e os benefícios que trariam a todos. Com essas atitudes temos percebido o quanto o trabalho integrado é importante para que o estudante tenha autonomia e consiga entender que conhecimento se adquire por meio de vivências e experiências, que podem e devem ser divididas.

Os projetos e as açóes que aqui compartilhamos seguem vivos e dinâmicos no cotidiano da escola, e esperamos que auxiliem a pensar sobre inciativas e processos educativos que, mesmo diante dos imensos desafios que nos assolam, seguem caminhos esperançosos na construção da escola pública, laica e democrática para todos(as).

Consideramos que as experiências aqui relatadas apontam iniciativas que nos aproximam da concepção de Educação Integral, que considera a formação humana em sua integralidade, na medida em que apostamos em projetos e práticas que incentivam a atuação dos estudantes baseada na autonomia e construção de processos criativos e de convivência. Também consideramos avanço a percepção por parte de alguns profissionais da escola, da necessidade do trabalho coletivo e de práticas voltadas para uma educação transformadora.

Contudo, ainda são identificados limites de atuação, tanto na esfera das políticas públicas ofertadas quanto na construção da identidade escolar, pois é necessário a efetivação de um projeto de escola que envolva todos os profissionais e que supere a mera extensão do currículo, dando a ver um tempo/espaço baseado em uma dinâmica curricular menos rígida e mais emancipadora.

\section{REFERÊNCIAS}

ARROYO, M. Currículo, território em disputa. 5. ed. Petrópolis: Vozes, 2013.

BRAH, A. Diferença, diversidade, diferenciação. Cadernos Pagu, Campinas, n. 26, p. 329-376, 2006. http://dx.doi.org/10.1590/S0104-83332006000100014

BRASIL. Lei no 13.005, de 26 de junho de 2014. Aprova o Plano Nacional da Educação - PNE e dá outras providências. Diário Oficial [da União], Brasília, Edição Extra, Seção I, p. 1, 2014. 
BRASIL. Ministério da Educação. Base Nacional Comum Curricular - BNCC. Brasília: INEP, 2017.

CAMPINAS. Resolução SME no 5, de 10 de março de 2014. Dispóe sobre a Organizaçáo do Trabalho Pedagógico das Unidades Educacionais integrantes do Projeto Piloto "Escola de Educaçāo Integral- EEI". Diário Oficial do Município, Campinas, Ano XLIV, n. 10.826, p. 4, 10 mar. 2014.

CAVALIERE, A.M.V. Educação integral: uma nova identidade para a escola brasileira? Educação \& Sociedade, Campinas, v. 23, n. 81, p. 247-270, dez. 2002. http://dx.doi.org/10.1590/S0101-73302002008100013

FERREIRA, A.B.H. Dicionário da língua portuguesa. 5. ed. Curitiba: Positivo, 2010.

LARROSA, J. Notas sobre a experiência e o saber de experiência. Revista Brasileira de Educação, Rio de Janeiro, n. 19, p. 20-28, 2002. http://dx.doi. org/10.1590/S1413-24782002000100003

\section{NOTAS}

1. Ideário da Escola Nova que veio para contrapor o que era considerado "tradicional".

2. Disponível em: <http://www.planalto.gov.br/ccivil_03/_ato2011-2014/2014/lei/ 113005.htm>. Acesso em: 28 maio 2018.

3. Disponível em: <http://basenacionalcomum.mec.gov.br/download-da-bncc>. Acesso em: 28 maio 2018.

4. Este trabalho faz parte do processo de formação realizado na escola pelo Grupo de Estudos e Pesquisa em Educaçáo Moral (GEPEM) da Universidade Estadual de Campinas (Unicamp) desde 2017, por meio de encontros semanais junto aos profissionais.

5. Pesquisa e conhecimento na escola (PESCO) é um programa da Prefeitura Municipal de Campinas que incentiva o desenvolvimento de pesquisas na escola.

Recebido em 20 de março de 2019.

Aprovado em $1^{\circ}$ de julho de 2019. 